\title{
SINGLE VERSUS MULTIPLE PULMONARY EMBOLI: DIFFERENT HAEMODYNAMIC AND BLOOD GAS RESULTS
}

\author{
J. Colin Kay, William H. Noble and Yahaya Z. Kadiri
}

\begin{abstract}
We evaluated haemodynamic and blood gas changes following the intravenous infusion of starch microemboli $(63-74 \mu)$. Comparisons were made between dogs receiving a single embolus and dogs receiving an equal quantity of embolus divided into small doses given at 30 minute intervals (multiple emboli). The most significant finding was that the same quantity of embolus produces different effects. In the dogs receiving a single embolus of $150 \mathrm{mg} \cdot \mathrm{kg}^{-1}$ of starch, $\mathrm{Pa}_{\mathrm{O}_{2}}$ fell from 11.3 to $7.6 \mathrm{kPa}\left(85\right.$ to 57 torr) $(\mathrm{p}<0.025)$ and $\dot{\mathrm{Q}}_{\mathrm{s}} / \dot{\mathrm{Q}}_{\mathrm{t}}$ increased from 11 to 34 per cent $(\mathrm{p}<0.01)$. In the multiple emboli dogs, after a total dose of $150 \mathrm{mg} \cdot \mathrm{kg}^{-1}$ of starch, there was a small but not significant fall in $\mathrm{Pa}_{\mathrm{O}_{2}}$ from 11.6 to $10.8 \mathrm{kPa}$ (87 to 81 torr), and $\mathrm{Q}_{s} / \dot{Q}_{1}$ did not change significantly. In the single embolus dogs $\dot{Q}$ increased significantly after an embolus of $100 \mathrm{mg} \cdot \mathrm{kg}^{-1}$ of starch $(\mathrm{p}<0.05)$. After a single embolus of $150 \mathrm{mg} \cdot \mathrm{kg}^{-1}, \dot{Q}$ was variable; 3 dogs showed a decrease, and 2 an increase, however the mean change was not significant. In the multiple emboli dogs, $\dot{Q}$ decreased significantly $(p<0.005)$.
\end{abstract}

KEY Words: EmBolism, pulmonary, haemodynamic effects, blood gas effects.

Pulmonary EMBoll in man and experimental animals produce a wide range of haemodynamic changes and severity of symptoms. Cardiac index has been reported as being normal, depressed, or elevated', and although hypoxaemia is frequently observed, some researchers have found cases of massive pulmonary embolism without arterial hypoxaemia. ${ }^{2}$

The mechanisms by which these haemodynamic changes are brought about are still not clear. Mechanical obstruction, neural and humoral mechanisms have been implicated..$^{3,4,5}$ Impaired gas exchange producing hypoxaemia after pulmonary emboli has been attributed to bronchoconstriction, ${ }^{6}$ opening of arterio-venous anastomosis in the embolized lung, ${ }^{7}$ impairment of diffusion, ${ }^{1}$ pulmonary oedema, ${ }^{8}$ and ventilation perfusion abnormalities. ${ }^{9-13}$

The primary haemodynamic consequence of embolism is a reduction in the available crosssectional area of the pulmonary arterial bed. ${ }^{13}$ Therefore it would seem logical to conclude, and some investigators have demonstrated, that the degree of haemodynamic compromise is a direct

J. Colin Kay, A.I.M.L.T.; William H. Noble, M.D., F.R.C.P.(C); Yahaya Z. Kadiri, M.D., F.R.C.P.(C), Department of Anaesthesia, University of Toronto, St. Michael's Hospital, 30 Bond Street, Toronto, Ontario, M5B 1W8

Address correspondence and reprint requests to: $\mathrm{Dr}$. W.H. Noble, Dept of Anaesthesia, St. Michael's Hospital, 30 Bond Street, Toronto, Ontario MSB IW8 function of the extent of embolism. ${ }^{14}$ However clinical observations indicate a disparity between the amount of embolic obstruction and the extent of haemodynamic compromise. ${ }^{2.15}$ Results from experimental embolization in animals are difficult to assess because they involve not only autologous blood clots but a wide range of foreign materials of different sizes including glass and plastic spheres, starch, lead pellets, barium sulphate, spores and seeds.

The spectrum of pulmonary embolism encompasses both the single massive embolus and showers of multiple emboli. Therefore, in this study we evaluated the haemodynamic and blood gas changes occurring in dogs receiving a single embolus compared to dogs receiving an equal quantity of embolus divided into small doses given at 30 minute intervals.

\section{METHODS}

Studies were done on 15 mongrel dogs (mean weight $21.9 \pm 1.2 \mathrm{~kg}$ ) anaesthetized with pentobarbitone (Abbott) $30 \mathrm{mg} \cdot \mathrm{kg}^{-1}$. The trachea was intubated and all dogs breathed room air spontaneously in the supine position. Pentobarbitone was administered intermittently as required to maintain light anaesthesia. The pulmonary artery, femoral artery and vein, and the left atrium were catheterized to monitor pressure continuously. ${ }^{10}$ All lines were kept patent by intermittent flushing with physiological saline, and no 
heparin was used. A large bore catheter was inserted into the left external jugular vein for injection of starch emboli ( $63-74 \mu$ in diameter) suspended in normal saline. The suspension was well mixed prior to injection. Arterial and mixed venous blood samples were obtained for blood gas analysis and all values were corrected to body temperature. Cardiac output $(\dot{Q})$ was determined using the thermodilution technique, and venous admixture fraction $\left(\dot{Q}_{s} / \dot{Q}_{1}\right)$ was calculated.

There were three groups of five dogs each, The first group (multiple emboli) received $50 \pm 6 \mathrm{mg}$. $\mathrm{kg}^{-1}$ aliquots of starch emboli at approximately 30 minute intervals, up to a maximum dose of $150 \pm 18 \mathrm{mg} \cdot \mathrm{kg}^{-1}$. The second group received a single starch embolus of $100 \pm 8 \mathrm{mg} \cdot \mathrm{kg}^{-1}$, and the third received a single starch embolus of 150 $\pm 0 \mathrm{mg} \cdot \mathrm{kg}^{-1}$. Measurements were recorded prior to embolization and approximately 10 to 20 minutes after the infusion of each embolus. when the pulmonary artery pressure was stable. The dogs were killed by injecting potassium chloride after the last set of data.

Comparisons are only made between the single embolus group and the multiple emboli group where there is no significant difference in the amount of starch given per $\mathrm{kg}$ of body weight, so differences are not due to the amount of starch given. Differences between groups were evaluated statistically using Student's " $t$ " test for paired and independent groups. If $p<0.05$ the differences were considered significant.

\section{RESULTS}

After the infusion of $50 \pm 6 \mathrm{mg} \cdot \mathrm{kg}^{-1}$ of starch emboli there were no significant changes. However it is interesting to note that in three out of five dogs the mean $\mathrm{Pa}_{\mathrm{O}_{2}}$ rose from 11 to $11.8 \mathrm{kPa}$ ( 83 to 89 torr).

After the infusion of $100 \pm 8 \mathrm{mg} \cdot \mathrm{kg}^{-1}$ or more,

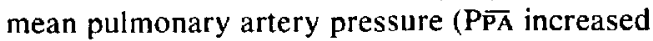
significantly in both the single embolus and multiple emboli dogs $(p<0.01)$, but there were no significant differences between the multiple emboli and the single embolus dogs. After a single embolus of $100 \pm 8 \mathrm{mg} \cdot \mathrm{kg}^{-1}, \overline{P A}$ increased from $2.4 \pm 0.26$ to $4.1 \pm 0.53 \mathrm{kPa}$ ( $18 \pm 2$ to $31 \pm$ $4 \mathrm{mmHg}$ ), and after $150 \pm 0 \mathrm{mg} \cdot \mathrm{kg}^{-1}$ from $2.4 \pm$ 0.26 to $4.3 \pm 0.66 \mathrm{kPa}$ ( $18 \pm 2$ to $32 \pm 5 \mathrm{mmHg}$ ). For any given quantity of starch embolus there was a wide range of $\overline{P A}$ values. After $100 \pm$ $8 \mathrm{mg} \cdot \mathrm{kg}^{-1}$ of starch, values ranged from 2.1 to $6 \mathrm{kPa}$ ( 16 to $45 \mathrm{mmHg}$ ); the dogs with the lowest $\mathrm{Pa}_{\mathrm{O}_{2}}$ having the highest $\mathrm{P} \overline{\mathrm{PA}}$. The decrease in $\mathrm{Pa}_{\mathrm{O}_{2}}$ was significantly greater in both groups receiving a single embolus ( $p<0.025$, Figure 1). Infusions of a single embolus of $100 \pm 8 \mathrm{mg} \cdot \mathrm{kg}^{-1}$ produced a significant fall in $\mathrm{Pa}_{\mathrm{O}_{2}}$ from $10.9 \pm 0.53$ to $8.4 \pm$ $1.07 \mathrm{kPa}$ (81 \pm 4 to $63 \pm 8$ torr). In the multiple emboli group, $\mathrm{Pa}_{\mathrm{O}_{2}}$ did not change significantly; after the infusion of two $50 \pm 6 \mathrm{mg} \cdot \mathrm{kg}^{-1}$ aliquots of embolus $\mathrm{Pa}_{\mathrm{O}_{2}}$ only fell from $11.6 \pm 0.53$ to 10.9 $\pm 0.79 \mathrm{kPa}(87 \pm 4$ to $82 \pm 6$ torr $)$. There was significant fall in $\mathrm{Pa}_{02}$ from $11.3 \pm 0.39$ to $7.6 \pm$ $0.53 \mathrm{kPa}(85 \pm 3$ to $57 \pm 4$ torr $)$ in the dogs receiving a single bolus of $150 \pm 0 \mathrm{mg} \cdot \mathrm{kg}^{-1}$ of starch. However $\mathrm{Pa}_{\mathrm{O}_{2}}$ only fell to $10.8 \pm 0.53 \mathrm{kPa}$ from $11.6 \pm 0.53 \mathrm{kPa}(81 \pm 4$ from $87 \pm 4$ torr $)$ in the multiple embolus group after a total infusion of $150 \pm 18 \mathrm{mg} \cdot \mathrm{kg}^{-1}$ of starch
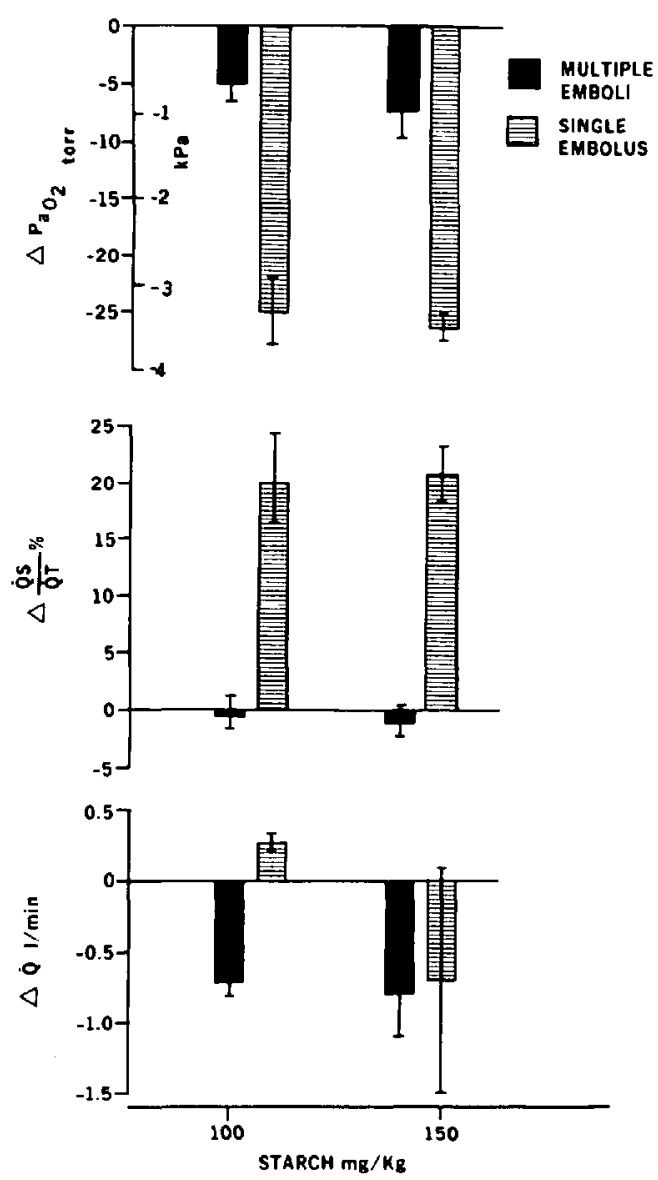

FIGURE 1. Changes in $\mathrm{Pa}_{\mathrm{O}_{2}}, \dot{\mathrm{Q}}_{\mathrm{s}} / \dot{\mathrm{Q}}_{\mathrm{t}}$ and $\dot{\mathrm{Q}}$ after starch emboli were injected. The single embolus doses were $100 \pm 8$ and $150 \pm 0 \mathrm{mg} \cdot \mathrm{kg}^{-1}$ of starch. The multiple emboli were given in $50 \pm 6 \mathrm{mg} \cdot \mathrm{kg}^{-1}$ aliquots. Comparisons were only made when there was no significant difference between the total amounts of starch injected. $I$ indicates \pm 1 SEM 
Venous admixture $\left(\dot{Q}_{s} / \dot{Q}_{t}\right)$ did not change significantly in the multiple emboli group, but increased significantly $(p<0.01)$ in both of the single embolus groups (Figure I). After a single embolus of $100 \pm 8 \mathrm{mg} \cdot \mathrm{kg}^{-1}, \dot{\mathrm{Q}}_{s} / \dot{\mathrm{Q}}_{\mathrm{t}}$ increased from $9 \pm 2$ to $30 \pm 9$ per cent and after a single embolus of $150 \pm 0 \mathrm{mg} \cdot \mathrm{kg}^{-1}$ of starch, $\dot{\mathrm{Q}}_{\mathrm{s}} / \dot{\mathrm{Q}}_{\mathrm{t}}$ increased from $11 \pm 2$ to $34 \pm 6$ per cent. The change in $\dot{\mathrm{Q}}_{s} / \dot{\mathrm{Q}}_{\mathrm{t}}$ was significantly greater in dogs receiving a single embolus (Figure 1) than in dogs receiving multiple emboli.

$\mathrm{P} \overline{\mathrm{O}}_{\mathrm{O}_{2}}$ fell significantly in both the single embolus dogs and the multiple emboli dogs. After a single embolus of $100 \pm 8 \mathrm{mg} \cdot \mathrm{kg}^{-1}, \mathrm{P} \overline{\mathrm{v}}_{\mathrm{O}_{2}}$ fell from $7.1 \pm 0.53$ to $5.9 \pm 0.79 \mathrm{kPa}(53 \pm 4$ to $44 \pm 6$ torr), and after a single embolus of $150 \pm 0 \mathrm{mg} \cdot \mathrm{kg}^{-1}$. $\mathrm{P} \overline{\mathrm{v}}_{\mathrm{O}_{2}}$ fell from $6.7 \pm 0.19$ to $4.9 \pm 0.39 \mathrm{kPa}(50 \pm$ 1.5 to $37 \pm 3$ torr). The fall in $P \bar{v}_{0_{2}}$ was not significantly different when the multiple emboli dogs were compared to the single embolus dogs.

The initial $\mathrm{Pa}_{\mathrm{CO}_{2}}$ was $5.6 \pm 0.26 \mathrm{kPa}(42 \pm$ 2 torr) and did not change significantly in any group. Arterial $\mathrm{pH}$ did not change significantly in the multiple emboli group or the group receiving a single starch embolus of $100 \pm 8 \mathrm{mg} \cdot \mathrm{kg}^{-1}$, but decreased from $7.38 \pm 0.03$ to $7.34 \pm 0.03(41.7 \pm$ 2.9 to $\left.45.7 \pm 2.9 \mathrm{nmol} / 1 \mathrm{H}^{+}\right)(\mathrm{p}<0.5)$ in the group receiving a single embolus of $150 \pm 0 \mathrm{mg} \cdot \mathrm{kg}^{-1}$.

Cardiac output decreased significantly $(\mathbf{p}<$ 0.005 ) in the multiple emboli group after the infusion of two $50 \pm 6 \mathrm{mg} \cdot \mathrm{kg}^{-1}$ aliquots, from 4.1 \pm 0.4 to $3.4 \pm 0.31 / \mathrm{min}$ (Figure 1). After the infusion of more starch it fell to $3.25 \pm 0.2 \mathrm{1} / \mathrm{min}$. However after the infusion of a single embolus of $100 \pm 8 \mathrm{mg} \cdot \mathrm{kg}^{-1}$ of starch, cardiac output increased significantly $(p<0.05)$ from $3.3 \pm 0.2$ to $3.5 \pm 0.11 / \mathrm{min}$. This increase in cardiac output was significantly different from the decrease observed in the multiple emboli dogs after receiving a total dose of $100 \pm 12 \mathrm{mg} \cdot \mathrm{kg}^{-1}$. In the group of dogs receiving a single bolus of 150 $\pm 0 \mathrm{mg} \cdot \mathrm{kg}^{-1}$ cardiac output changes were variable; three dogs showed a decrease and two an increase. but the mean change was not significant.

\section{Discussion}

The most significant finding of this study is that the same quantity of starch emboli can produce different effects on $\mathrm{Pa}_{\mathrm{O}_{2}}$, venous admixture $\left(\dot{Q}_{s} / Q \mathrm{Q}\right)$, and cardiac output, depending upon whether it is injected as a single embolus within five seconds, or divided into aliquots of $50 \pm$
$6 \mathrm{mg} \cdot \mathrm{kg}^{-1}$ injected approximately 30 minutes apart.

Why the single embolus dogs had a greater fall in $\mathrm{Pa}_{\mathrm{O}_{2}}$ and increase in venous admixture than the multiple emboli dogs is not clear. But the difference cannot be due to greater pulmonary embolization since both groups were embolized with the same quantity and size of embolus. The greater fall in $\mathrm{Pa}_{0_{2}}$ is also not due to a greater decrease in $P \bar{v}_{O_{2}}$, because although the $P \bar{v}_{0_{2}}$ fell significantly in the single and multiple emboli dogs there were no significant differences in the absolute values or the decrease in $P \bar{v}_{\mathrm{O}_{2}}$.

It is of interest to consider why these differences in $\mathrm{Pa}_{\mathrm{O}_{2}}$ and $\dot{\mathrm{Q}}_{3} / \dot{\mathrm{Q}}_{\mathrm{t}}$ occurred. Kadiri17 demonstrated that starch or blood clot emboli are preferentially distributed to the vasculature of ventilated lung. Malik's also demonstrated that emboli obstruct the dependent lung vessels. As the cardiac output and pulmonary artery pressure increased after a single bolus of $100 \pm 8 \mathrm{mg} \cdot \mathrm{kg}^{-1}$, mechanical blockage of these well perfused areas must lead to a redistribution of blood flow. There was a marked increase in venous admixture after a single bolus. But venous admixture measured during spontaneous respiration, breathing room air, includes the shunt-like effect of areas of lung having an inequality of ventilation with respect to perfusion such that the ventilation perfusion ratio (V/Q) is reduced, and areas of the lung that function as a true right to left shunt (areas of atelectasis, $\dot{V} / \dot{Q}=0$ ). Therefore the redistributed blood flow could cause an increase in $\dot{Q}_{s} / \dot{Q}_{t}$ by perfusing areas of low $\dot{V} / \dot{Q}$ or areas of atelectasis. Dantzker $^{10}$ found that $V / \dot{Q}$ abnormalities could account for almost all of the arterial hypoxaemia after pulmonary emboli and Malik ${ }^{18}$ found the hypoxaemia after pulmonary embolism to be consistent with ventilation/perfusion imbalance.

Alveolar hypoxia causes constriction of pulmonary arterial vessels (hypoxic pulmonary vasoconstriction [HPV]), which diverts blood away from hypoxic areas of the lung so as to maintain reasonably constant ventilation/perfusion ratios. Interference with this response would increase venous admixture and decrease $\mathrm{Pa}_{0.2}$. Hypocapnia and alkalosis are known to diminish the HPV response, ${ }^{19,20}$ but in this study $\mathrm{Pa}_{\mathrm{CO}_{2}}$ did not change significantly, and there was no alkalosis present. However, HPV can be blunted in the presence of an increase in pulmonary artery pressure.$^{20}$ It is possible, therefore, that the pulmonary hypertension resulting from pulmonary embolism will tend to overcome the hypoxic 
pulmonary vasoconstriction and re-open vessels in the hypoxic lung areas, redistributing blood flow to areas of low ventilation, thus creating areas of low $\dot{V} / \dot{Q}$. This would also cause an increase in the calculated venous admixture and a drop in $\mathrm{Pa}_{\mathrm{O}_{2}} \cdot{ }^{17}$

Why, therefore, is there a difference between the single and multiple emboli dogs? In the single embolus dogs hypoxaemia was evident within five minutes of embolization. This fall was too rapid to be accounted for by pulmonary oedema. Embolization was the same, and it is unlikely that there would be any significant differences in the amount of pre-embolic atelectasis or degree of hypoxic pulmonary vasoconstriction present. Therefore, by exclusion it appears that the differences have to be due to different distributions of ventilation/perfusion ratios after emboli. In the multiple emboli dogs, the initial embolus did not produce a significant change in mean pulmonary artery pressure. However, it must have blocked pulmonary capillaries and redistributed blood flow. This would result in changes in the ventilation/perfusion ratios of the lungs. Also, subsequent emboli will distribute to different lung areas than would a single embolus of equal quantity.

The difference in $\mathrm{Pa}_{\mathrm{O}_{2}}$ between the single and multiple emboli groups and the small decrease in $\mathrm{Pa}_{\mathrm{O}_{2}}$ in the multiple emboli dogs is consistent with clinical reports of patients having angiographically proven embolism and little or no hypoxaemia. ${ }^{3}$

In the multiple emboli dogs after the infusion of a total dose of $100 \pm 8 \mathrm{mg} \cdot \mathrm{kg}^{-1}$ or more there was a significant drop in cardiac output; however when $100 \pm 8 \mathrm{mg} \cdot \mathrm{kg}^{-1}$ was injected as a single embolus there was a significant increase in cardiac output. This difference may be due to the systemic arterial hypoxaemia present in the single embolus group.

The most consistent observation after a pulmonary embolism of $100 \pm 8 \mathrm{mg} \cdot \mathrm{kg}^{-1}$ or more was an increase in pulmonary artery pressure. Neurogenic reflexes and release of vasoactive substances have been cited as contributing to pulmonary hypertension after pulmonary embolism. ${ }^{4.5}$ Other investigators emphasize the role of mechanical obstruction and have demonstrated that the extent of haemodynamic compromise is dependent upon the percentage of cross sectional area of the pulmonary arterial bed. ${ }^{3}$ It appears that about 50 per cent obstruction of the pulmonary bed is necessary before pulmonary hypertension is observed. ${ }^{13}$ In our study, injection of $50 \pm$
$6 \mathrm{mg} \cdot \mathrm{kg}^{-1}$ of starch did not produce a significant rise in $P_{\overline{P A}}$ and cardiac output remained constant. This implies that there was a degree of reserve in the compliance of the pulmonary vascular bed. However, injection of $100 \pm 8 \mathrm{mg} \cdot \mathrm{kg}^{-1}$ or more of starch produced a significant increase in $\mathrm{PA}$ ( $\mathrm{p}$ $<0.01$ ). There was a significant, but not good, correlation $(r=0.43, p<0.05)$ between the

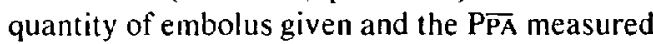
after single and multiple doses of starch emboli (Figure 2). For any given quantity of starch there was a wide range of $\mathrm{P} \overline{\mathrm{PA}}$ values, the dogs with the lowest $\mathrm{Pa}_{\mathrm{O}_{2}}$ having the highest $\mathrm{PA}$. This scatter may be associated with a hypoxic-induced response increasing $\mathrm{P} \overline{\mathrm{PA}}$. However, it can also be explained by the theory suggested by Kadiri ${ }^{17}$ and Fisher " that the increase in P $\overline{P A}$ redistributes blood flow to areas of HPV, increasing venous admixture and lowering $\mathrm{Pa}_{\mathrm{O}_{2}}$. After embolization with $50 \pm 6 \mathrm{mg} \cdot \mathrm{kg}^{-1}$ or more of starch as a single embolus, there was a good correlation $(\mathrm{r}=$ $-0.76, p<0.01$ between $\bar{P} \overline{P_{A}}$ and the arterial oxygen tension (Figure 3 ).

In this study we have demonstrated that the haemodynamic and blood gas changes that occur after pulmonary embolism do not depend upon the degree of embolization. The same quantity and size of embolus produced significantly different results depending upon how it was administered. This observation is important for future design of pulmonary embolism experiments. It emphasizes the necessity for carefully controlled studies. When groups of dogs are to be compared, it is essential that they receive not only the same amount of embolus, but it should be administered in exactly the same manner to each group.

Also our data indicate that single emboli pro-

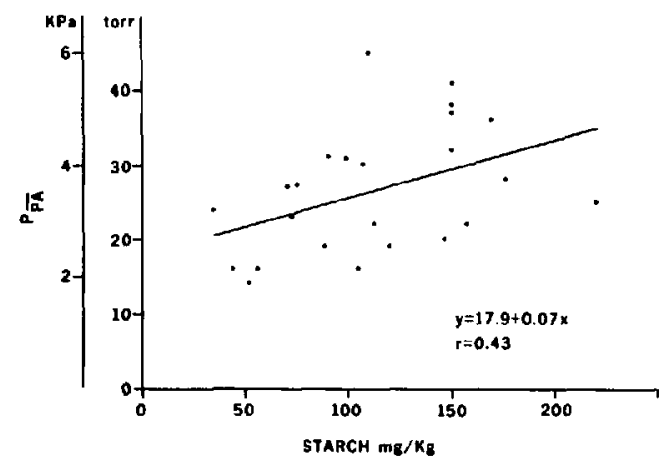

Figure 2 The effect of starch emboli, both single and multiple doses. on mean pulmonary artery pressure. 


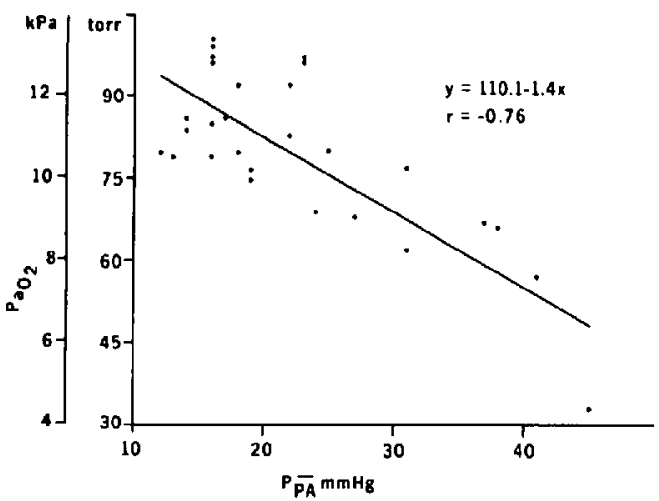

FIGURE 3 Relationship between mean pulmonary artery pressure and $\mathrm{Pa}_{\mathrm{O}_{2}}$ after the injection of a single starch embolus.

duce different haemodynamic and blood gas changes than multiple emboli. While there are fundamental differences between starch cmboli in dogs and blood clot emboli in patients, these data may explain the clinical finding of no hypoxaemia in the presence of angiographically doc. umented emboli. ${ }^{2}$

\section{ACKNOWLEDGEMENTS}

The authors are grateful for the expert technical assistance of $G$. Caskennette, E. Janssen, and $\mathbf{C}$. Mindorff. We thank $\mathbf{P}$. Slusarenko for typing, and Dr. R.J. Byrick for reviewing the manuscript. This project was supported by the York-Toronto Lung Association and the Medical Research Council of Canada, Grant No. MA-7106.

\section{REFERENCES}

1. Marshall, R. \& Allison, P.R. Pulmonary embolism by small blood clots: Physiologic responses in the anaesthetised dog. Thorax 17:289 (1962).

2. RoBIN, E.D. Overdiagnosis and overtreatment of pulmonary embolism: The emperor may have no clothes. Ann. Int. Med. 87: 775 (1977).

3. Williams, M.H. JR. Mechanical versus reflex effects of diffuse pulmonary embolism in anesthetized dogs. Circ. Res. 4: 325 (1956).

4. WEIDNER, M.G. JR \& LiGHT, R.A. Role of the autonomic nervous system in the control of the pulmonary vascular bed: 1II. Further studies in experimental pulmonary embolism. Ann. Surg. 147: 895 (1958).

5. Comroe, J.H., Van Lingen, B., Stroud, R.C. \& RUNCORONI, A. Reflex and direct cardiopulmonary effects of 5-OH-tryptamine (serotin): Their possible role in pulmonary embolism and coronary thrombosis. Am. J. Physiol. 173: 379 (1953).

6. Clarke, S.W., Graf, P.D. \& Nadel, J.A. In vivo visualisation of small airway constriction after pulmonary microembolism in cats and dogs. $J$. Appl. Physiol. 29: 646 (1970).

7. Niden, A.H. \& Aviado, D.M. Effects of puimonary embolism on the pulmonary circulation with special reference to arterio-venous shunts in the lung. Circ. Research 4: 67 (1956).

8. Swenson, E.W., Llamas, R. \& Ring, G.C. Hypoxemia and edema of the lung in experimental pulmonary thromboembolism. Pulmonary Embolic Disease: Proceedings of the Symposium. Edited by Sasahara, A.A. \& Stein, M., New York, Grune \& Stratton, pp. 170-180 (1964).

9. CALDINI, P. Pulmonary haemodynamics and arterial oxygen saturation in pulmonary embolism. J. Appl. Physiol. 20: 184 (1965).

10. Dantzker, D.R., Wagner, P.D. Tornabene, N.P., ALAZRAKI, N.P. \& WEST, J.B. Gas exchange after pulmonary thromboembolisation in dogs. Circ. Research 42: 92 (1978).

11. Fisher, J., Noble, W.H. \& Kay, J.C. Hypoxemia following pulmonary embolism: A dog model of altering regional perfusion. Anesthesiology 54 : 204 (1981).

12. Levy, S.E., Stein, M., Totten, R.S., BruderMAN, I., WESSLER, S. \& RoBIN, E.D. Ventilationperfusion abnormalities in experimental pulmonary embolism. J. Clin. Invest. 44: 1699 (1965).

13. Moser, K.M. Pulmonary Embolism. Am. Rev. Resp. Dis. 1/5: 829 (1977)

14. DeXTER, L. \& SMITH, G.T. Quantitative studies of pulmonary embolism. Am. J. Med. Sci. 247: 641 (1964).

15. McIntyre, K.M. \& Sasahara, A.A. Hemodynamic and ventricular responses to pulmonary embolism. Pulmonary Emboli: Progress in Cardiovascular diseases. Edited by Sasahara, A.A., Sonnenblick. E.H. \& Lesch, M. New York, Grune \& Stratton 17: 175 (1974).

16. Noble, W.H. \& KAY, J.C. Cardiac catheterization in dogs. Can. Anaesth. Suc. J. 21:616 (1974).

17. Kadiri, Y.Z., KaY, J.C., Kovacs, K. \& Noble, W.H. Pulmonary embolism distribution to ventilated and unventilated lungs in the dog: a cause of hypoxaemia. Can. Anaesth. Soc. J. 27: 216 (1980).

18. Malik, A.B. \& VanderZee, Hoyte. Time course of pulmonary vascular response to microembolization. J. Appl. Physiol. 43: 51 (1977).

19. MaLIK, A.B. \& KidD, B.S.L. Independent effects of changes in $\mathrm{H}^{+}$and $\mathrm{CO}_{2}$ concentrations on hypoxic pulmonary vasoconstriction. J. Appl. Physiol. 34 (3): 318 (1973).

20. Benumof, J.L. \& Wahrenbrock, E.A. Blunted hypoxic pulmonary vasoconstriction by increased lung vascular pressures. J. Appl. Physiol. 38: 846 (1975).

\section{RÉSUMÉ}

On a évalué sur l'hémodynamie et les gaz du sang le retentissement causé par la perfusion intro-veineuse de microembolies d'amidon (63-74 $\mu$ ). Les auteurs ont comparé entre eux des chiens qui recevaient un seul embole à des chiens qui recevaient une quantité égale d'emboles 
divisés en petites doses et administrés à des intervalles de 30 minutes (embolies multiples). La conclusion la plus remarquable a été que la même dose d'emboles pourrait produire des effets

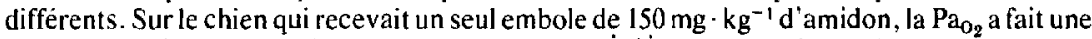
chute de 11.3 à $7.6 \mathrm{kPa}(85$ à 57 torr $)(\mathrm{p}<0.025)$ et le $\dot{\mathrm{Q}}_{\mathrm{s}} / \dot{\mathrm{Q}}_{\mathrm{t}}$ a augmenté de $1 \mathrm{l}$ à 34 pour cent $(\mathrm{p}<$ 0.01 ). Sur le chien chez qui on avait fractionné les emboles, les auteurs ont constaté après une dose totale de $150 \mathrm{mg} \cdot \mathrm{kg}^{-1}$ damidon une petite chute non significative de la $\mathrm{Pa}_{\mathrm{O}_{2}}$ de 11.6 à $10.8 \mathrm{kPa}\left(87\right.$ à 81 torr), et un $\dot{\mathrm{Q}}_{\mathrm{s}} / \dot{\mathrm{Q}}_{1}$ inchangé. Chez les chiens ayant reçu un seul embole, le débit cardiaque a augmenté de façon significative après un embole de $100 \mathrm{mg} \cdot \mathrm{kg}^{-1}$ d'amidon $(\mathrm{p}<0.05)$. Après un seul embole de $150 \mathrm{mg} \cdot \mathrm{kg}^{-1}$, le débit cardiaque a été variables; il a diminué pour trois chiens, augmenté pour deux, mais ce changement n'a pas été jugé significatif. Chez les chiens à emboles multiples, le débit cardiaque a augmenté de façon significative $(\mathrm{p}<0.005)$. Ces résultats soulignent l'importance et la nécessité de protocoles rigoureux lorsqu'on fait l'étude de l'embolie pulmonaire expérimentalc. 